\title{
Determination of Some Agricultural Properties of Second Product Sweet Sorghum [Sorghum bicolor (L.) Moench] in Sanlıurfa Conditions
}

\author{
Erdal Erbil (Corresponding author) \\ GAP Agricultural Research Institute, Haliliye, Sanliurfa, Turkey \\ E-mail: erdal.erbil@tarimorman.gov.tr \\ Cemile Adiyaman \\ GAP Agricultural Research Institute, Haliliye, Sanliurfa, Turkey \\ E-mail: cemile.adiyaman@tarimorman.gov.tr \\ Aysegul Efendioglu Celik \\ Black Sea Agricultural Research Institute, Tekkekoy, Samsun, Turkey \\ E-mail: aysegul.celik@tarimorman.gov.tr \\ Halil Hatipoglu \\ GAP Agricultural Research Institute, Haliliye, Sanliurfa, Turkey \\ E-mail: halilhatipoglu63@ hotmail.com \\ Mine Aksoy \\ Black Sea Agricultural Research Institute, Tekkekoy, Samsun, Turkey \\ E-mail: mine.aksoy@tarimorman.gov.tr \\ Mustafa Acar \\ Black Sea Agricultural Research Institute, Tekkekoy, Samsun, Turkey \\ E-mail: mustafaacar@tarimorman.gov.tr \\ Mahmut Dok \\ Black Sea Agricultural Research Institute, Tekkekoy, Samsun, Turkey \\ E-mail: mahmut.dok@tarimorman.gov.tr
}

\begin{abstract}
Turkey is dependent on foreign countries for oil and petroleum products. Although our country is considered to be rich in renewable energy sources, it cannot use its existing potential sufficiently. Our country is suitable for the cultivation of many plants due to its geographical location. For this reason, alternative energy plants which are not grown in our country but which are thought to adapt to the ecological conditions of our country should be taken into production design. Sweet sorghum is basically a sugar plant as well as food, feed, fiber, energy, biofuels has a wide use. Bioethanol is produced from the stem of the sweet sorghum with a high sugar content and the residual pulp is processed and evaluated as biomass after the juice is taken.

In this study, which was carried out as a second product under the ecological conditions of Sanliurfa in 2016-1017, bioethanol yields of these varieties, energy values of some agricultural properties related to yield and yield were investigated. The experiment was designed as a randomized block design with four replications, the parcels were arranged between the rows of $70 \mathrm{~cm}$, the row was $20 \mathrm{~cm}$ and the row length was $10 \mathrm{~m}$. When the number of days and flowering periods of varieties were examined, the earliest species were Urja (4.25-4.75 days) and the earliest flowering species were PHS 12-10 (85.25-88 days. The sugar ratio (brix value) of the cultivars used in the study varied between $17.87 \%$ (Top 76-6) and $12.17 \%$ (Dale).
\end{abstract}

Keywords: Adaptation, Biomass, Sweet sorghum, Sanliurfa Renewable energy

DOI: $10.7176 /$ JSTR/6-07-03 


\title{
Şanlıurfa Koşullarında İkinci Ürün Tatlı Sorgum [Sorghum bicolor (L.) Moench] 'un Bazı Tarımsal Özelliklerinin Belirlenmesi
}

\begin{abstract}
Özet
Türkiye, fosil yakıtlar ve türevleri açısından net ithalatçı bir ülkedir. Ülkemiz yenilenebilir enerji kaynakları bakımından zengin bir potansiyele sahip olmasına rağmen bu kaynaklarını yeterince kullanamamaktadır. Coğrafi konumu bakımından birçok tarımsal ürününyetişmesine uygun ekolojiye sahiptir. Bu nedenle araştırma kurumlarımız tarafından ülkemizde yetiştiriciliği yapılmayan fakat ülkemizin iklim şartlarına uyum sağlayabileceği düşünülen alternatif enerji bitkilerinin de deneme üretimlerinin yapılması gerekmektedir. Temelde bir şeker bitkisi olmasının yanında tatlı sorgum, gıda, yem, lif, enerji, biyoyakıt olarak geniş bir kullanım alanına sahiptir. Tatlı sorgum bitksinin yüksek şeker oranına sahip sap kısmından biyoetanol üretilmekte ve özsuyu alındıktan sonra kalan posa işlenip biyokütle olarak değerlendirilmektedir.

Şanlıurfa ekolojik şartlarında 2016-1017 yıllarında ikinci ürün olarak yürütülen bu çalışmada altı tatlı sorgum (Dale, M81-E, PHS 12-10, Urja, Top 76-6, Theis) çeşidi kullanılarak bu çeşitlerin bazı tarımsal ve teknolojik özellikleri incelenmiştir. Deneme tesadüf blokları deneme desenine göre dört tekrarlamalı olarak kurulmuş, parseller sıra aras $70 \mathrm{~cm}$, sıra üzeri $20 \mathrm{~cm}$ ve sıra uzunluğu $10 \mathrm{~m}$ olacak şekilde beş sıralı olarak düzenlenmiştir. Çeşitlerin çıkış gün sayısı ve çiçeklenme sürelerine bakıldığında en erken çıkış yapan çeşit Urja (4.25-4.75 gün) ve en erken çiçeklenen çeşit PHS 12-10 (85.25-88 gün) olmuştur. Araştırmada kullanılan çeşitlerin şeker oranları (brix değeri) \%17.87 (Top 76-6) ile \%12.17 (Dale) arasında değişişmektedir.
\end{abstract}

Anahtar Kelimeler: Adaptasyon, Biyokütle, Tatı Sorgum, Şanlıurfa, Yenilenebilir enerji,

\section{Giriş}

Biyokütle, bitki ve hayvan metabolizmanının kaynağı olarak tanımlanan, bitkilerde genelikle güneș enerjisinden faydalanarak fotosentez yardımıyla depolanabilen organik karbon oluşumlarının genel adıdır. Biyokütle, ekosistemi oluşturan çesitli türlerden oluşan bir topluma ait yaşayan organizmaların yaşam süresince sahip oldukları fosil kaynaklı kütle miktarıdır.(Eren,2011). Biyokütle, karada ve suda yaşayan bitkiler, hayvan artıkları, kentsel atıklar, besin endüstrisi ve tarıma dayalı endüstri atıklarını içeren tüm organik maddeler olarak tanımlanır. Biyokütle doğrudan enerji kaynağı olarakta kullanılabilmekte olup, katı, gaz ve sıvı forma dönüştürlerek yakıta çevrilebilmektedir Biyokütleden elde edilen enerjiye ise biyokütle enerjisi denir. (Karayılmazlar ve ark., 2011).

Petrol ticaret açığının azaltılmasında kullanılacak biyoyakıt üretimi için gerekli olan tarımsal kaynağın yerelde üretilmesinin gerekliliği yapılan ulusal ve uluslararası çalışmalarda ortaya konulmuştur (Lynd et al., 1991, Lynd, 1996 ). Bu şekilde üretimi yapılacak enerji bitkilerinden hem biyoyakıt üretilmiş olacak, hem de üretim esnasında ortaya çıkan organik atıklar biyokütle olarak değerlendirilerek ikinci bir enerji kaynağı elde edilmiş olacaktır.

Tarım alanında enerji tarımı adı verilen bir tarım türü ortaya çıkmaktadır. Dünyada son yıllarda yenilenebilir enerji bitkileri tarımı üzerine çalışmalar yoğunlaşmış, birçok ülke bu konuda hızlı yol almıştır. Ülkemizde yenilenebilir enerji kaynaklarına verilen desteklerin $(\% 0,7)$, dünya ortalamasının (\% 2-3) altında olduğu görülmekle birlikte, bunu geliştirmeye yönelik çalışmaların da yapılmadığ 1 dikkatleri çekmektedir (Yaşar, 2009).

C4 enerji bitkileri arasında en çok yetiştiriciliği yapılan enerji tarımında ülkemizde henüz çok bilinmeyen, dünyada ise hızla yaygınlaşmaya başlayan bitkilerden biri de tatlı sorgumdur. Graminea familyasına dahil olanTatlı sorgum [Sorghum bicolor (L.) Moench], anavatanı Kuzey ve Doğu Afrika olan, C4 fotosentezine sahip tek yıllık hem enerji hem de yem bitkisidir. Koca darı türünün bir alt tiptir (Acar ve Akgün, 2009). Fizyolojik olgunluk süresi 90-140 gün arasında değişen kısa gün bitkisidir. Çok etkili bir kök sistemine sahip olan bitki aynı zamanda yüksek büyüme hızına sahiptir. Gelişkin kök sistemi sayesinde kuraklığa tolerant ve su gereksinimi biyokütlesine oranla düşüktür. Adaptasyon kabiliyeti iyi, yüksek biyokütle verimine sahiptir (Köppen et al., 2009). Kumlu, killi, tuzlu alkali topraklarda da tarımı yapılabilen her türlü toprak tipine tamamen adapte olabilen ender bitkilerdendir (Guiying et al., 2003, Reddy and Sanjana, 2003). Tatlı sorgum, biyoetanol üretimi için en ümit verici olan tür olup, gelişmekte olan ülkelerde enerji tarımı için en çok araştırılan bitkiler arasındadır (Balat et al., 2008). Yüksek sap verimi ve sapında (\% 5-15) içerdiği yüksek orandaki şeker sayesinde biyoetanol üretiminde çok başarılı bir şekilde kullanılabileceği Avrupa Birliği ülkeleri, Amerika, Brezilya, Çin,

25 I P a g e

www.iiste.org 
Hindistan, Etiyopya gibi ülkelerde yapılan tarımsal ve endüstriyel çalışmalarla belirlenmiştir. Enerji bitkisi olmasının yanı sıra konsantre şurup olarak iyi ve ucuz bir şeker kaynağıdır. Bunların dışında insan beslenmesinde, hayvan yemi olarak, elyaf yapımında, yüksek kaliteli kağıt yapımında kullanılan en iyi hammaddelerden biridir (Köppen et al., 2009, Guiying et al., 2003). Tanesi gluten içermediği için tahıla alerjisi olan kişiler tarafindan unundan faydalanılır (Grassi, 2001). Ayrıca tatlı sorgumdan biyoetanol üretiminde yan ürün olarak elde edilen $\mathrm{CO}_{2}$ tıpta, yangın söndürmede, karbonatlı içeceklerde ve kuru buz imalatında kullanılmaktadır. Tatlı sorgum kullanılarak üretimi yapılabilen bir diğer ürün de yakıt pili teknolojisinde kullanılan hidrojendir (Eren, 2011). Tatlı sorgumdan elde edilen ürünler ve kullanım şekilleri Tablo 1.'de verilmiştir.

Enerji üretiminin ve tüketiminin sürdürülebilir kalkınma kavramı çerçevesinde gerçekleștirilmesi, günümüzün en önemli hedeflerinden birisi olmuştur. Bu bağlamda insanlık, sürdürülebilir kalkınma ve daha iyi yaşam şartları arayışına devam ettikçe, yenilenebilir enerji üretimi, dünya çapında önceliğini sürdürmeye devam edecektir.

$\mathrm{Bu}$ çalışma ile; Tatlı sorgum [Sorgum bicolor (L.) Moench] çeşitlerinin Şanlıurfa koşullarına adaptasyonu, verim ve verimle ilişkili bazı tarımsal ve teknolojik özellikleri incelenerek yüksek adaptasyon kabiliyeti iyi çeşitlerin belirlenmesi amaçlanmıştır. Bir çok ülkede biyoetanol üretiminde başarılı bir şekilde kullanılan tatlı sorgumun ülkemiz tarımına da kazandırılması, üretiminin teşvik edilmesi ve geliştirilmesi hedeflenmiştir. Bu sayede biyoetanol üretimi için alternatif bir enerji bitkisi olan tatlı sorgumun üretim deseni içinde yer alması amaçlanmıştır.

Tablo 1. Tatlı sorgumdan elde edilen ürünler ve kullanım şekilleri.

\begin{tabular}{ll}
\hline Kısımları & Kullanım şekilleri \\
\hline Taneler & Gida, besleme, birinci nesil biyoetanol \\
Özsu & Şeker ve birinci nesil biyoetanol \\
Küspesi & Besleme, küspe, biyoenerji, ikinci nesil biyoetanol, kompost gübre \\
Yaprakları & Besleme, biyoenerji, ikinci nesil biyoetanol, gübre \\
\hline
\end{tabular}

\section{Materyal ve Metot}

\subsection{Materyal}

2.1.1. Deneme Yerinin Genel Özellikleri

Deneme, Şanlıurfa ilinde yer alan GAP Tarımsal Araştırma Enstitüsü Müdürlüğ̈̈’ne ait Koruklu-Talat Demirören Araştırma İstasyonu deneme alanında yürütülmüştür.

Denemenin yürütüldüğü araştırma istasyonu, $36^{\circ} 42^{\prime}$ kuzey enlemi, $38^{\circ} 58^{\prime}$ doğu boylamında olup denizden yüksekliği 410 m'dir (Anonim, 2003b).

\subsubsection{Deneme Alanının Toprak Özellikleri}

Deneme, bölgede geniş yayılım alanına sahip ve araştırma istasyonunun tamamında yer alan Harran Toprak Serisinde yürütülmüştür. Bu seri toprakları, alüviyal ana materyalli, düz ve düze yakın eğimli, derin profilli topraklardır. Tipik kırmızı profilleri killi tekstürlü ve tüm profil çok kireçlidir. A,B,C horizonlu topraklar olup, pH 7.3 ile 7.8 arasında, organik madde içeriği düşük, katyon değişim kapasitesi yüksektir. Katyon değişim kapasitesi kil içeriğine bağlı olarak alt katmanlara doğru artmaktadır (Dinç ve ark. 1988). Ekim yapılan parselleri temsil edecek şekilde 0-30 cm derinliğinden alınan toprak numuneleri harmanlanmıştır. Elde edilen harman GAP Tarımsal Araştırma Enstitüsü bünyesindeki Toprak Laboratuvarında analiz edilmiştir. Analiz sonuçları Tablo 2.'de verilmişsir.

Tablo 2. Deneme alanına ait bazı toprak özellikleri

\begin{tabular}{ccccccccc}
\hline Yıllar & $\begin{array}{c}\text { Toprak } \\
\text { Derinliği (cm) }\end{array}$ & $\begin{array}{c}\text { Ec } \\
(\mathbf{d s} / \mathbf{m})\end{array}$ & $\begin{array}{c}\text { Kirec } \\
(\boldsymbol{\%})\end{array}$ & $\mathbf{p H}$ & $\begin{array}{c}\text { Fosfor } \\
(\mathbf{k g} / \mathbf{d a})\end{array}$ & $\begin{array}{c}\text { Potasyum } \\
(\mathbf{k g} / \mathbf{d a})\end{array}$ & $\begin{array}{c}\text { Organik } \\
\text { Madde }\end{array}$ & $\begin{array}{c}\text { Suya } \\
\text { Doy. }(\boldsymbol{\%})\end{array}$ \\
\hline 2015 & $0-30$ & 1.12 & 31.2 & 7.88 & 3.98 & 123.2 & 1.45 & 65 \\
2016 & $0-30$ & 1.27 & 29.8 & 7.89 & 3.74 & 121.1 & 1.11 & 68 \\
2017 & $0-30$ & 1.13 & 28.9 & 7.65 & 4.68 & 119.4 & 1.37 & 71 \\
\hline
\end{tabular}

\subsubsection{Deneme Alanının İklim Özellikleri}

Şanlıurfa karasal iklim bölgesine girmekle beraber, Akdeniz ikliminin etkisi görülmektedir. Yazları kurak ve sıcak, kışları 1lık geçmektedir. Yaz mevsiminde çoğunlukla Basra alçak basınç merkezine yerleşmiş olan kurak ve sıcak tropikal hava kütlesinin etkisinde kalmaktadır. Gündüz sıcakllğ $140^{\circ} \mathrm{C}$ 'nin üzerine çıkmaktadır. Bağıl nemin çok düşük oluşu buharlaşmayı arttırmaktadır. (Atalay ve Mortan, 2006). Uzun yıllar içinde gerçekleşen ortalama iklim verileri ve deneme yıllarına ait ortalama sıcaklık ve

26| P a g e 
maksimum sıcaklık değerleri Tablo 3.' de verilmiştir. Aylık ortalama sıcaklıklar ortalama $32{ }^{\circ} \mathrm{C}$ civarındadır.

Tablo 3. Deneme yılları ve uzun yıllar ortalamalarına ait sıcaklık verileri

\begin{tabular}{|c|c|c|c|c|c|c|c|c|}
\hline \multirow[t]{2}{*}{ Aylar } & \multicolumn{2}{|c|}{2015} & \multicolumn{2}{|c|}{2016} & \multicolumn{2}{|c|}{2017} & \multicolumn{2}{|c|}{$\begin{array}{l}\text { Uzun Yillar } \\
\text { Ortalaması }\end{array}$} \\
\hline & $\begin{array}{l}\text { Ort.S1c. } \\
\left({ }^{\circ} \mathrm{C}\right)\end{array}$ & $\begin{array}{l}\text { Max.Sic. } \\
\left({ }^{\circ} \mathrm{C}\right)\end{array}$ & $\begin{array}{l}\text { Ort.Sic. } \\
\left({ }^{\circ} \mathrm{C}\right)\end{array}$ & $\begin{array}{c}\text { Max.Sic. } \\
\left({ }^{\circ} \mathrm{C}\right)\end{array}$ & $\begin{array}{l}\text { Ort.S1c. } \\
\left({ }^{\circ} \mathrm{C}\right)\end{array}$ & $\begin{array}{c}\text { Max.S1c. } \\
\left({ }^{\circ} \mathrm{C}\right)\end{array}$ & $\begin{array}{l}\text { Ort. Sic. } \\
\left({ }^{\circ} \mathrm{C}\right)\end{array}$ & $\begin{array}{c}\text { Max. Sic } \\
\left({ }^{\circ} \mathrm{C}\right)\end{array}$ \\
\hline Ocak & 5,9 & 17,4 & 5,1 & 15,3 & 4,9 & 14,6 & 5,5 & 21,6 \\
\hline Şubat & 8,1 & 18,2 & 11,2 & 25,2 & 6,5 & 22,7 & 6,9 & 25,5 \\
\hline Mart & 11,7 & 24,5 & 13,4 & 26,1 & 12,7 & 23,9 & 10,7 & 29,4 \\
\hline Nisan & 15,5 & 33,4 & 20,1 & 33,0 & 16,6 & 32,3 & 16,1 & 36,4 \\
\hline Mayıs & 23,1 & 38,1 & 23,2 & 36,3 & 22,7 & 36,5 & 22,1 & 40,3 \\
\hline Haziran & 27,4 & 39,0 & 29,6 & 42,8 & 29,1 & 42,7 & 28,1 & 44,1 \\
\hline Temmuz & 32,2 & 43,9 & 32,2 & 44,1 & 33,0 & 44,7 & 31,9 & 46,8 \\
\hline Ağustos & 30,9 & 44,4 & 32,0 & 43,0 & 31,1 & 45,3 & 31,3 & 46,2 \\
\hline Eylül & 28,3 & 41,0 & 25,4 & 38,8 & 27,5 & 40,8 & 26,8 & 42,1 \\
\hline Ekim & 21,4 & 35,2 & 20,5 & 34,2 & 19,5 & 31,1 & 20,1 & 37,8 \\
\hline Kasım & 13,0 & 24,6 & 11,3 & 25,6 & 12,5 & 26,2 & 12,8 & 30,8 \\
\hline Aralık & 7,3 & 18,6 & 5,5 & 15,1 & 7,9 & 15,7 & 7,5 & 26,0 \\
\hline
\end{tabular}

\subsubsection{Bitki materyali}

Araştırmada özel bir firmadan temin edilen altı (Dale, Theis, M 81E, Top 76-6, PHS 12-10, Urja) tatlı sorgum [Sorghum bicolor (L.) moench] çeşidi kullanılmıştır. Çeşit özellikleri aşağıda verilmiştir.

Dale: Orta erkenci bir çeşittir. Özellikle yaprak antraknozu ve sap çürüklüğü olmak üzere hastalıklara karşı dayanıklıdır. Pamuk zararlılarına karşı dayanıklıdır. Salkım, silindir şeklinde olup sık ve diktir. Tohumu ters yumurta şeklinde olup, rengi açık ve koyu kırmızımsı kahverengidir. Endosperm nişastalıdır. Şurup üretimi için yetiştirilmekte, sap verimi 50-55 t/ha, brix oranı ise \% 15 'tir. Hamur olum süresi 126 gündür.

Theis: Geç olgunlaşan bir çeşittir. Hastalık ve zararlılara dayanıklıdır. Salkım çok sık olmayıp diktir. Püsküller biraz uzundur. Kavuzların uç kısımları keskindir. Olgunlaşma zamanında kavuzlar tohumu tutmaz ve harmanlama kolay olur. Tohumlar genelde kahverengi ve küre şeklindedir. Yapraksız sap verimi yaklaşık 50 t/ha'dır. Brix oranı \% 16’dır.

M 81E: Geç olgunlaşan bir çeşit olup şurup ve fermente edilebilir şeker için yetiştirilir. Salkım çok sık olmayıp diktir. Yaprak antraknozu ve sap çürüklüğüne oldukça dayanıklıdır. Ancak mısır cücelik virüsü ve pasa karşı hassastır. Pamuk zararlılarına karşı dayanıklıdır. Tohumlar kahverengi ve ovaldir. Tanenin nişasta oranı oldukça yüksektir. Yapraksız sap verimi 50 t/ha'dır. Brix oranı \% 15'dir.

Top 76-6: Orta erkenci bir çeşittir. Şurup üretimi için kullanılır. Yatmaya dayanıklıdır. Özellikle yaprak antraknozuna dayanıklıdır. Mısır cücelik virüsü çok nadir de olsa etkili olabilmektedir. Salkım çok sık olmayıp diktir. Tohumlar elips şeklindedir. Kavuzlar koyu kahverengidir. Brix oranı \% 17'dir. Sap verimi $54 \mathrm{t} / \mathrm{ha}$ 'dır.

PHS 12-10: Orta erkenci bir çeşittir. Yatmaya, hastalık ve zararlılara dayanıklıdır. Tohumlar elips şeklindedir. Sap verimi 50-60 t/ha, brix oranı \% 15'tir.

Urja: Hastalık ve zararlılara karşı dayanıklıdır. Yatmaya dayanıklıdır. Salkım çok sık değildir. Brix oranı \% 15'tir. Yetiştirildiği bölgelere göre sap verimi büyük değişkenlik gösterip 42-88 t/ha arasında değişmektedir.

\subsection{Metot}

Denemenin arazi çalışmaları, Şanlıurfa ilinde yer alan GAP Tarımsal Araştırma Enstitüsü Müdürlüğü’ne ait Koruklu-Talat DEMIRÖREN Araştırma İstasyonu deneme alanında yürütülmüştür. Denemenin bütün laboratuar analizleri ve biyokütle çalışmaları Karadeniz Tarımsal Araştırma Enstitüsü bünyesinde bulunan Enerji Tarımı Araştırma Merkezi Laboratuarında yapılmıştır. 


\subsubsection{Deneme Deseni}

Denemede 6 farklı tatlı sorgum çeşidi kullanılmıştır. Deneme tesadüf blokları deneme desenine göre 4 tekrarlamalı olarak kurulmuş, parseller sıra arası $70 \mathrm{~cm}$, sıra üzeri $20 \mathrm{~cm}$ ve sıra uzunluğu $10 \mathrm{~m}$ $\left(10 \times 0.7 \times 5=35 \mathrm{~m}^{2}\right)$ olacak şekilde beş sıralı olarak düzenlenmiştir. Tekerrürler arasında $3 \mathrm{~m}$ mesafe bırakılmıştır. Parsel hasat alanı $8 \times 0.7 \times 3=16.8 \mathrm{~m}^{2}$ dir.

\subsubsection{Denemede İncelenen Özellikler}

1. Çıkış gün sayısı (gün): Ekimden itibaren her bir parseldeki tohumların \% 050 'sinin çıkış yaptığ tarih alınmıştır (Anonim, 2010).

2. Çiçeklenme süresi (gün): Ekim tarihi ile parseldeki bitkilerin \%50'sinde salkımların görüldüğü tarihe kadar geçen süre gün olarak kaydedilmiştir (Anonim, 2010).

3. Fizyolojik olgunlaşma süresi (gün) : Ekim tarihi ile fizyolojik olgunlaşma tarihi arasında geçen süre kaydedilmiştir (Anonim, 2010).

4. Bitki boyu (cm): Biçim öncesi her parselde hasat alanından tesadüfe bağlı olarak seçilen 10 bitkinin, toprak yüzeyinden salkımın en uç noktası arasında kalan dikey mesafe ölçülmüş ve ortalaması alınarak cm cinsinden ifade edilmiştir (Anonim, 2010).

5. Kardeş sayısı (adet/bitki) : Her parselden tesadüfen seçilen 10 bitkide kardeşler sayılarak ortalamaları alınmıştır (Soleymani et al. 2013) .

6. Şeker oranı (brix) (\%): Her parselden alınan $5 \mathrm{~kg}$ bitki paçal şurupta refraktometre cihazı ile briks derecesi yüzde (\%) olarak belirlenmiştir (Anonim, 2010

\subsection{3 İstatistiki analiz ve değerlendirme}

Projenin ilk yılı olan 2015 yılının eylül ayında meydana gelen şiddetli rüzgâr ve firtına nedeniyle deneme tamamen kırılıp yatmıştır. Bu yıl hiçbir paramatre için gözlem alınamamış ve 2015 yılı istatistiki değerlendirmeye dâhil edilmemiştir.

Araştırmada 2016-2017 yıllarında elde edilen veriler JMP 7.1 istatistik paket programından yararlanılarak varyans analizine tabi tutulmuş ve değerlendirilmiştir.

\section{Araştırma Sonuçları ve Tartışma}

3.1. Çıkış gün sayısı (gün)

Şanlıurfa koşullarında ikinci ürün olarak yetiştirilen tatlı sorgum çeşitlerinde çıkış gün sayılarına ait varyans analiz sonucu oluşan gruplar, birleştirilmiş varyans analiz sunucu oluşan gruplar ve varyasyon katsayısı (\% Cv) değerleri Tablo 4’te verilmiştir. 2016 ve 2017 yıllarına ait çıkış gün sayılarına ait varyansların homojenliği Levene homojenlik testiyle test edilmiş olup, yapılan homojenlik testinde varyansların homojen olduğu görülmüş (Sig. 0.08>0.05) ve birleşik varyans analizi uygulanmıştır.

Tablo 4 incelendiğinde çıkış gün sayıları bakımından çeşitler arasındaki farklılıklar 2016 ve 2017 yılları ile yılların birleşik varyans alanaliz sonuçlarına göre istatistiki açıdan önemli bulunmuştur. 2016 ve 2017 y1llarında Theis çeşidi 6.75-6.25 gün sayıları ile en geç çıkış yapan çeşit olmuştur. 2016 da Urja çeşidi 4.75 gün ile en erken çıkış yapan çeşit olmuş, Dale, M 81E ve PHS 12-10 çeşitleri ile aynı grupta yer almıştır. 2017 yılında ise Dale çeşidi 4.03 gün ile en erken çıkış yapan çeşit olurken, PHS 12-10 ve Urja çeşidi ile aynı grupta yer almaktadır.

Birleştirilmiş analiz sonucunda yapılan LSD testine göre en erken çıkış yapan çeşitler Dale (4.50 gün) ve Urja (4.50 gün) aynı grupta yer almışlardır. Theis ise 6.50 gün ile en geç çıkış yapan çeşit olmuştur.

Tablo 4. Farklı tatlı sorgum çeşitlerinde çıkış gün sayısına ait 2016-2017 yılları ve birleştirilmiş analiz sonucu yapılan LSD testine göre oluşan gruplar.

\begin{tabular}{lccc}
\hline & \multicolumn{3}{c}{ Çıkış Gün Sayısı (gün) } \\
\hline Çeşitler & $\mathbf{2 0 1 6}^{* *}$ & $\mathbf{2 0 1 7 * *}$ & Birleşik $^{* *}$ \\
\cline { 2 - 4 } 1-Dale & $5,00 \mathrm{~b}$ & $4,03 \mathrm{c}$ & $4,50 \mathrm{c}$ \\
2-Theis & $6,75 \mathrm{a}$ & $6,25 \mathrm{a}$ & $6,50 \mathrm{a}$ \\
3-M 81E & $5,00 \mathrm{~b}$ & $5,25 \mathrm{~b}$ & $5,12 \mathrm{~b}$ \\
4-Top 76-6 & $6,50 \mathrm{a}$ & $5,50 \mathrm{ab}$ & $6,00 \mathrm{a}$ \\
5-PHS 12-10 & $5,25 \mathrm{~b}$ & $4,25 \mathrm{c}$ & $4,75 \mathrm{bc}$ \\
6-Urja & $4,75 \mathrm{~b}$ & $4,25 \mathrm{c}$ & $4,50 \mathrm{c}$ \\
\hline LSD & 0,82 & 0,82 & 0,525 \\
CV(\%) & 9,83 & 10,07 & 9,84 \\
\hline \multicolumn{4}{l}{}
\end{tabular}




\section{2. Çiçeklenme süresi (gün)}

Araştırmada kullanılan tatlı sorgum çeşitlerinde çiçeklenme süresi, ekim tarihi ile parseldeki bitkilerin \% 50'sinde salkımların görüldüğü tarihe kadar geçen süre gün olarak hesaplanmış olup, çeşitlere ait varyans analiz sonucu uygulanan LSD testine göre oluşan gruplar, birleştirilmiş varyans analiz sunucu oluşan gruplar ve varyasyon katsayısı (\% Cv) değerleri Tablo 5.'da verilmiştir. Yıllara ait çiçeklenme sürelerine ait varyanslarının homojenliği Levene homojenlik testiyle test edilmiş olup, yapılan homojenlik testinde varyansların homojen olduğu görüldüğünden (Sig. 0.32>0.05) yıllar birleştirilerek varyans analizi yapılmıştır.

Yıllar ayrı ayrı değerlendirildiğinde ve yılların birleştirilmiş analizine göre çeşitler arasındaki fark istatistiki olarak önemli bulunmuştur.

Tablo 5 incelendiğinde ikinci çeşit olan Theis 2016 ve 2017 y1llarında $121.75-115.50$ değerleri ile en yüksek çiçeklenme gün sayısına sahipken. PHS 12-10 çeşidi 2016 ve 2017 yıllarında 85.25-88 gün ile en erken çiçelenen çeşit olmuştur. Birleştirilmiş analiz sonucunda yapılan LSD testine göre en erken çiçeklenme süresine 86.63 gün ile PHS 12-10 çeşidi ulaşırken, en uzun çiçeklenme süresine Theis çeşidi 118.62 gün ile ulaşmıştır. M 81E ve Top 76-6 çeşitleri Theis çeşidi ile aynı grupta yer almıştır.

Tablo 5. Farklı tatlı sorgum çeşitlerinde çiçeklenme süresine ait 2016-2017 yılları ve birleştirilmiş analiz sonucu yapılan LSD testine göre oluşan gruplar

\begin{tabular}{lccc}
\hline & \multicolumn{3}{c}{ Çiçeklenme Süresi (gün) } \\
\hline Çeşitler & $\mathbf{2 0 1 6}^{* *}$ & $\mathbf{2 0 1 7}^{* *}$ & Birleşik $^{* *}$ \\
\cline { 2 - 4 } 1-Dale & $105,25 \mathrm{~b}$ & $97,43 \mathrm{c}$ & $101,87 \mathrm{c}$ \\
2-Theis & $121,75 \mathrm{a}$ & $115,50 \mathrm{a}$ & $118,62 \mathrm{a}$ \\
3-M 81E & $118,25 \mathrm{a}$ & $114,50 \mathrm{a}$ & $116,37 \mathrm{a}$ \\
4-Top 76-6 & $119,50 \mathrm{a}$ & $114,50 \mathrm{a}$ & $117,00 \mathrm{a}$ \\
5-PHS 12-10 & $85,25 \mathrm{c}$ & $88,00 \mathrm{~d}$ & $86,63 \mathrm{~d}$ \\
6-Urja & $108,5 \mathrm{~b}$ & $107,00 \mathrm{~b}$ & $107,75 \mathrm{~b}$ \\
\hline LSD & 7,28 & 6,68 & 4,525 \\
CV(\%) & 4,4 & 3,78 & 4,10 \\
\hline \multicolumn{4}{c}{$\%$}
\end{tabular}

\subsection{Fizyolojik olgunlaşma süresi (gün)}

Şanlıurfa koşullarında ikinci ürün olarak yetiştirilen farklı tatlı sorgum çeşitlerinde fizyolojik olgunlaşma süresine ait varyans analiz sonucu uygulanan LSD testine göre oluşan gruplar, birleştirilmiş varyans analiz sunucu oluşan gruplar ve varyasyon katsayısı (\% Cv) değerleri Tablo 6.'de verilmiştir. Yıllara ait fizyolojik olgunlaşma sürelerine ait varyansların homojenliği Levene homojenlik testiyle test edilmiş olup, yapılan homojenlik testinde varyansların homojen olduğu görülmüş (Sig. 0.42>0.05) ve yıllar birleştirilerek varyans analizi uygulanmıştır.

Tablo 6. Farklı tatlı sorgum çeşitlerinde fizyolojik olgunlaşma sürelerine ait 2016-2017 yılları ve birleştirilmiş analiz sonucu yapılan LSD testine göre oluşan gruplar

\begin{tabular}{lccc}
\hline & \multicolumn{3}{c}{ Fizyolojik Olgunlaşma Süresi (gün) } \\
\hline Çeşitler & $\mathbf{2 0 1 6}^{* *}$ & $\mathbf{2 0 1 7}^{* *}$ & Birleşik** $^{*}$ \\
\cline { 2 - 4 } 1-Dale & $168,50 \mathrm{c}$ & $167,06 \mathrm{c}$ & $168,12 \mathrm{c}$ \\
2-Theis & $195,25 \mathrm{a}$ & $189,75 \mathrm{ab}$ & $192,50 \mathrm{a}$ \\
3-M 81E & $182,75 \mathrm{~b}$ & $184,75 \mathrm{~b}$ & $183,75 \mathrm{~b}$ \\
4-Top 76-6 & $192,25 \mathrm{a}$ & $192,00 \mathrm{a}$ & $192,12 \mathrm{a}$ \\
5-PHS 12-10 & $167,00 \mathrm{c}$ & $168,25 \mathrm{c}$ & $167,62 \mathrm{c}$ \\
6-Urja & $164,75 \mathrm{c}$ & $168,25 \mathrm{c}$ & $166,50 \mathrm{c}$ \\
\hline LSD & 9,13 & 7,22 & 5,41 \\
CV $(\%)$ & 3,46 & 2,43 & 2,97 \\
\hline \multicolumn{4}{c}{} \\
& $*: \% 5$ önem seviyesine göre önemli,**: \%1 önem seviyesine göre önemli
\end{tabular}

Yıllar ayrı ayrı değerlendirildiğinde ve yılların birleştirilmiş analizine göre çeşitler arasındaki fark istatistiki olarak önemli bulunmuştur. Tablo 6 incelendiğinde 2016 yılında. Theis çeşidi 195.25 gün en geç olgunlaşan çeşit olurken Urja çeşidi 164.75 günlük süre ile en erken olgunlaşan çeşit olmuştur. 2017 y1lında Top 76-6 çeşidi 192 günlük süre ile en geç olgunlaşan çeşit olmuştur. Urja 166.50 gün ile en erken olgunlaşan çeşit olup. PHS 12-10 (167.62 gün) ve Dale (168.12 gün) çeşitleri ile aynı istatistiki grupta yer almıştır. Birleştirilmiş analiz sonucunda yapılan LSD testine göre en erken fizyolojik olgunlaşma süresine Urja çeşidi (166.50 gün), en uzun olgunlaşma süresine Theis çeşidi (192.50 gün)

29 | P a g e

www.iiste.org 
ulaşmıştır.

\subsection{Bitki boyu (cm)}

Araştırmada ele alınan çeşitlerin bitki boylarına ait varyans analiz sonucu uygulanan LSD testine göre oluşan gruplar, birleştirilmiş varyans analiz sunucu oluşan gruplar ve varyasyon katsayısı $(\% \mathrm{Cv})$ değerleri Tablo 7'de verilmiştir. Yıllara ait bitki boylarına ait varyansların homojenliği Levene homojenlik testiyle test edilmiş olup, yapılan homojenlik testinde yıllara ait varyansların homojen olmadığ 1 görülmüş (Sig. $0.0017<0.05$ ) ve yıllar ayrı ayrı değerlendirilmiştir.

Tablo 7 incelendiğinde. 2016 yılında bitki boyu bakımından çeşitler arasındaki fark istatistiki olarak önemli bulunmamış, bitki boyları 255.17-426.25 cm arasında değişmiştir. 2017 yılında ise çeşitler arasındaki bitki boyu farkları istatistiksel açıdan önemli bulunmuş olup. Dale çeşidi $388.02 \mathrm{~cm}$ ile en yüksek bitki boyuna ulaşırken Top $76-6$ çeşidi $340.85 \mathrm{~cm}$ ile en düşük bitki boyuna ulaşmıştır.

Tablo 7. Farklı tatlı sorgum çeşitlerinde bitki boylarına ait 2016-2017 yılları analiz sonucu yapılan LSD testine göre oluşan gruplar

\begin{tabular}{lcc}
\hline & \multicolumn{2}{c}{ Bitki Boyu (cm) } \\
\hline Çeşitler & $\mathbf{2 0 1 6}$ & $\mathbf{2 0 1 7} * *$ \\
\cline { 2 - 3 } 1-Dale & 285,73 & $362,50 \mathrm{bcd}$ \\
2-Theis & 415,5 & $388,02 \mathrm{a}$ \\
3-M 81E & 426,25 & $375,45 \mathrm{ab}$ \\
4-Top 76-6 & 372,75 & $340,85 \mathrm{~d}$ \\
5-PHS 12-10 & 255,175 & $349,45 \mathrm{~cd}$ \\
6-Urja & 295,18 & $362,20 \mathrm{bc}$ \\
\hline LSD & Ö,D & 22,29 \\
CV(\%) & 20,66 & 3,96 \\
\hline \multicolumn{2}{c}{$* \% 5$ önem seviyesine göre önemli,**: \%1 önem seviyesine göre önem }
\end{tabular}

\subsection{Kardeş sayısı (adet/bitki)}

Araştırmada ikinci ürün olarak yetiştirilen tatlı sorgum çeşitlerinde kardeş sayılarına ait varyans analiz sonucu uygulanan LSD testine göre oluşan gruplar, birleştirilmiş varyans analiz sonucu oluşan gruplar ve varyasyon katsayısı (\% Cv) değerleri Tablo 8'de verilmiştir. Yıllara ait kardeş sayılarına ait varyansların homojenliği Levene homojenlik testiyle test edilmiş olup, yapılan homojenlik testinde varyansların homojen olduğu görülmüş (Sig. $0.0034<0.05)$ ve birleşik varyans analizi uygulanmamıştır. Yıllar kendi içinde değerlendirildiğinde kardeş sayıları bakımından çeşitler arasındaki fark 2016 yılında varyans analiz sonuçlarına göre istatistiki olarak önemsiz. 2017 yılında ise önemli bulunmuştur. Tablo 8'e göre 2016 yılında en çok kardeşlenen çeşit Urja (3.60 adet/bitki) çeşidi olmuştur. 2017 yılında kardeş sayıları 3.05-2.51 adet arasında değişmiştir. Top 76-6 (3.05 adet/bitki) çeşidi en yüksek kardeş sayısına sahip olup, en düşük kardeş sayısı Dale (2.51 adet/bitki) çeşidinden alınmıştır.

Tablo 8. Farklı tatlı sorgum çeşitlerinde kardeş sayılarına ait 2016-2017 yılları analiz sonucu yapılan LSD testine göre oluşan gruplar

\begin{tabular}{lcc}
\hline & \multicolumn{2}{c}{ Kardeş Sayısı (kardeş/bitki) } \\
\hline Çeşitler & $\mathbf{2 0 1 6}$ & $\mathbf{2 0 1 7}$ \\
\cline { 2 - 3 } 1-Dale & 2,84 & $2,51 \mathrm{~b}$ \\
2-Theis & 3,01 & $2,75 \mathrm{ab}$ \\
3-M 81E & 3,10 & $2,85 \mathrm{ab}$ \\
4-Top 76-6 & 3,40 & $3,05 \mathrm{a}$ \\
5-PHS 12-10 & 2,95 & $2,62 \mathrm{~b}$ \\
6-Urja & 3,60 & $2,60 \mathrm{~b}$ \\
\hline LSD & Ö,D, & 0,35 \\
CV(\%) & 16,72 & 7,84 \\
\hline \multicolumn{2}{c}{$* \% 5$ önem seviyesine göre önemli,**: \%1 önem seviyesine göre önemli }
\end{tabular}

\section{6. Şeker Oranı (\%)}

Araştırmada ele alınan çeşitlerin şeker oranlarına ait varyans analiz sonucu uygulanan LSD testine göre oluşan gruplar ve varyasyon katsayısı (\% Cv) değerleri Tablo 9.'da verilmiştir. Yıllara ait şeker oranlarına ait varyansların homojenliği Levene homojenlik testiyle test edilmiş olup, yapılan homojenlik testinde varyansların homojen olmadığı görülmüş (Sig. 0.0018<0.05) ve birleşik varyans analizi uygulanmamıştır. 
Tablo 9. Farklı tatlı sorgum çeşitlerinde şeker oranlarına ait 2016-2017 yılları analiz sonucu yapılan LSD testine göre oluşan gruplar

\begin{tabular}{lcc}
\hline & \multicolumn{2}{c}{ Şeker Oranı (brix)(\%) } \\
\hline Çeşitler & $\mathbf{2 0 1 6} * *$ & $\mathbf{2 0 1 7} * *$ \\
1-Dale & $14,82 \mathrm{~b}$ & $12,17 \mathrm{~d}$ \\
2-Theis & $14,06 \mathrm{c}$ & $16,45 \mathrm{ab}$ \\
3-M 81E & $14,65 \mathrm{bc}$ & $15,80 \mathrm{~b}$ \\
4-Top 76-6 & $15,35 \mathrm{~b}$ & $17,87 \mathrm{a}$ \\
5-PHS 12-10 & $16,83 \mathrm{a}$ & $14,27 \mathrm{c}$ \\
6-Urja & $14,04 \mathrm{c}$ & $13,62 \mathrm{~cd}$ \\
\hline LSD & 0,73 & 1,56 \\
CV(\%) & 3,28 & 6,21 \\
\hline \multicolumn{2}{c}{$* \% 5$ önem seviyesine göre önemli, **: \%1 önem seviyesine göre önemli }
\end{tabular}

Tablo 9 incelendiğinde şeker oranları bakımından çeşitler arasındaki farklılıklar 2016-2017 yıllarında istatistiksel olarak önemli bulunmuştur. Tablo 9'a göre 2016 yılında en yüksek şeker oranı PHS 12-10 (\% 16.83) çeşidinden, en düşük şeker oranı Urja (\% 14.04) çeşidinden alınmıştır. 2017 yılına bakıldığında en yüksek şeker oranı Top 76-6 (\% 17.87) çeşidinden, en düşük oran ise Dale (\% 12.17) çeşidinden alınmıştır. Bütün çeşitler istatistiki olarak farklı gruplarda yer almıştır.

\section{Sonuc}

Şanlıurfa ekolojik koşullarında yazlık ikinci ürün olarak yetiştirilen tatlı sorgum çeşitlerinin bölge koşullarına adaptasyonu, biyoetanol verimi, biyokütlenin enerji değeri, verim ve verimle ilişkili bazı tarımsal özelliklerinin belirlenmesi amacıyla yürütülen çalışmada aşağıdaki sonuçlar elde edilmiştir.

4.1. Çıkış gün sayısı (gün): Çeşitlerin çıkış gün sayılarına bakıldığında en erken çıkış yapan çeşitler. Urja ve Dale (4.75-4.03 gün) ve en geç çıkış (6.75-6.25 gün) yapan çeşit ise Theis olmuştur. Tatlı sorgumda iyi bir çıkışın sağlanması için sulamanın çok iyi yapılması gerekmektedir. Tohumlar çok küçük olduğu için ekim derinliğinin iyi ayarlanması ve toprak neminin yeterli olması gerekir. Çalışmamızda çıkışla ilgili herhangi bir sorun yaşanmamış olup çıkışlar üniform olmuştur.

4.2. Çiçeklenme süresi (gün): Araştırmada yıllar itibariyle en yüksek çiçeklenme gün sayıs1 121.75115.50 gün arasında değişmiş, en erken çiçeklenme süresi ise 85.25-88.0 gün olarak kaydedilmiştir. Reddy ve ark. (2005). Hindistan'da farklı tatlı sorgum çeşitlerinin kullanıldığı araştırmada çiçeklenme gün sayısının (\% 50) 69-88 gün arasında değiştiği belirtilmektedir. Girgin (2012). Bornova koşullarında tatlı sorgumda farklı azot dozlarının etkisini incelediği çalışmasında çiçeklenme gün süresinin 57.3-51.3 gün arasında değiştiğini kaydetmiştir. Araştırmacının kullandığı çeşit. Keller, çok erkenci bir çeşit olup, araştırmamızda kullandığımız çeşitler ise orta erkenci (PHS 12-10. Top 76-6. Dale) ve geçci (Theis. M 81E) özelliklere sahiptir. Bu nedenle araştırıcıların tespit ettiği gün sayısı ile bu çalışma sonucu bulunan değerler farklılık göstermektedir.

4.3. Fizyolojik olgunlasma süresi (gün): Çeşitler arasında en erken fizyolojik olgunluğa erişen çeşitler. Urja (164.75 gün) ve Dale (167.06 gün) olurken, en geç olgunlaşan çeşitler ise Top 76-6 (192 gün) ve Theis (195.25 gün) olmuştur. Girgin (2012). Bornova koşullarında tatlı sorgumda farklı azot dozlarının etkisini incelediği çalışmasında fizyolojik olgunlaşma gün süresinin 116.7-103.7 gün arasında değiştiğini kaydetmiştir. Araştırmacının kullandığı çeşit, Keller, çok erkenci bir çeşit olup, araştırmamızda kullandığımız çeşitler ise orta erkenci (PHS 12-10. Top 76-6. Dale) ve geçci (Theis. M 81E) özelliklere sahiptirler. Bu nedenle araştırıcının tespit ettiği fizyolojik olgunlaşma süresi ile bu çalışma sonucu bulunan değerler arasında büyük fark görülmektedir. Bu farklılığın çeşit özelliğinden kaynaklandığı kanısına varılmaktadır.

4.4. Bitki boyu $(\mathrm{cm})$ : Çalışmamızda en yüksek bitki boyuna M $81 \mathrm{E}(426.25 \mathrm{~cm})$ ve Theis $(388.02 \mathrm{~cm})$ çeşitleri ulaşırken. en düşük bitki boyu ise $255.17 \mathrm{~cm}$ ile PHS 12-10 çeşidinden alınmıştır. Clegg ve ark. (1986). Nebraska koşullarında tatlı sorgumda bitki boyunun 394 cm'ye kadar ulaştığını; Tsuchihashi ve Goto (2004), Wray, Keller ve Rio çeşitlerini kullandıkları çalışmalarında ekimden 80 gün sonraki ortalama bitki boyunun 320 cm'ye ulaştığı; Geren ve ark., (2011), bir çeşit tatlı sorgum kullandıkları çalışmalarında bitki boyunun 204 cm'ye; Girgin (2012), İzmir koşullarında tatlı sorgumda farklı azot dozlarının etkisini incelediği çalışmasında bitki boyunun 225-198 cm arasında değiştiği belirtmiştir. Bulgularımız bazı araştırmacıların bulguları ile uyumlu iken bazı araştırmacıların bulgularından daha

31 | P a g e

www.iiste.org 
yüksek çıkmıştır. Araştırmalarda kullanılan Keller çeşidi, çok erkenci ve kısa boylu bir çeşit olup, araştırmamızda kullandığımız çeşitler ise uzun boyludur. Boy, her ne kadar çevre şartlarından etkilenen bir parametre ise de aslında bir çeşit özelliğidir. Tatlı sorgumun sap kısmı sıkılarak biyoetanol elde edildiği için bitki boyunun uzun olması elde edilecek biyoetanol oranının artması anlamına gelmektedir. Bu nedenle biyokütle ve biyoetanol üretimi için seçilecek çeşitlerin uzun boylu olması tercih edilmelidir.

4.5. Kardeş Saylsı (adet/bitki): Tatlı sorgum kardeşlenen bir bitki türüdür. Araştırmada en çok kardeş sayısını Urja (3.6 adet/bitki) ve Top 76-6 (3.05 adet/bitki) çeşitleri oluştururken. en az kardeş sayısı Dale (2.84-2.51adet/bitki) çeşidinde meydana gelmiştir. Geren ve ark., (2011), yaptıkları çalşşmada kardeş sayısını ortalama 3.2 adet/bitki olarak bildirmişlerdir. Değerlerimiz araştırmacıların bulguları ile uyumludur.

4.6. Şeker oranı: En yüksek şeker oranı PHS 12-10 (\%16.83) ve Top 76-6 (\%17.87) çeşitlerinden, en düşük şeker oranı Urja (\%14.04) ile Dale (\%12.17) çeşitlerinden elde edilmiştir.

\section{Kaynaklar}

ACAR. R. VE AKGÜN. N.. 2009. Şeker darısının (Sorghum bicolor (L.) Moench var. saccharatum) yeşil ot verimi ve verim öğelerine farklı azot dozlarının etkisi. Türkiye VIII. Tarla Bitkileri Kongresi. Hatay. 1: 637-640. 19-22 Ekim 2009.

ANONIM. 2003b. 2002 su yılı hidrometeorolojik rasat verileri. Şanlıurfa- Harran Ovası. Köy Hizmetleri Şanlıurfa Araştırma Enstitüsü Müdürlüğ̈̈ Yayınları

ANONIM. 2010. Tarımsal Değerleri Ölçme Denemeleri Teknik Talimatı. Sorgum (Sorghum spp.). T.C. Tarım ve Köyişleri Bakanlığı Tarımsal Üretim ve Geliştirme Genel Müdürlüğü Tohumluk Tescil Ve Sertifikasyon Merkezi Müdürlüğ̈̈. 1-13.

ATALAY. I.. MORTAN. K.. 2006. Türkiye Bölgesel Coğrafyası. Inkılap Kitabevi. 3. Baskı. Ankara. 620 s.

BALAT. M.. BALAT. H.. ÖZ. C.. 2008. Progress in bioethanol processing. Progress in Energy and Combustion Science. 34: 551-573.

EREN. Ö.. 2011. Çukurova bölgesinde tatlı sorgum (sorghum bicolor (L.) moench) üretiminde yaşam döngüsü enerji ve çevresel etki analizi. Çukurova Üniversitesi Fen Bilimleri Enstitüsü. Tarım Makinaları Anabilim Dalı. Doktora Tezi. 1-196.

CLEGG. M.D.. GORZ. H.J.. MARANVILLE. J.W. AND HASKINS. F.A.. 1986. Evaluation of agronomic and energy traits of Wray sweet sorghum and the N39 x Wray hybrid. Energy in Agriculture. 5:49-54pp.

DINÇ. U.. ŞENOL. S.. SAYIN. M.. KAPUR. S. VE GÜZEL. N.. 1988. Güneydoğu Anadolu Bölgesi Toprakları (GAT). I. Harran Ovası . TÜBİTAK. Tarım Ormancılık Araştırma Grubu Güdümlü Araştırma Projesi kesin sonuç raporu,TOAG - 534. Adana.

GEREN. H.. AVCIOĞLU. R.. KAVUT. Y.T.. SAKINOĞLU ORUÇ. Ç.. ÖZTARHAN. H.. 2011. İkinci ürün olarak yetiştirilen şeker darısının (Sorghum bicolor (L.) Moench var. Saccharatum) verim ve verimle ilgili diğer bazı özellikleri üzerinde bir ön araştırma. Türkiye IV. Tohumculuk Kongresi. Samsun. 2: 525-530. 14-17 Haziran 2011.

GIRGINN. V.Ç.. 2012. Bornova koşullarında ikinci ürün olarak yetiştirilen tatlı sorgum(sorghum bicolor L.)'da farklı azot dozlarının bazı tarımsal ve teknolojik özelliklere etkisi üzerinde araştırmalar. Ege Üniversitesi Fen Bilimleri Enstitüsü. Tarla Bitkileri Anabilim Dalı. Yüksek lisans tezi. 1-42.

GRASSİ. G.. 2001. Sweet sorghum : One of the best world food-feed-energy crop. Erişim: 31.10.2013 http://web2.etaflorence.it/cms/ uploads/ETA/pubblicazioni/brochures_ online/ LAMNET_sweet_sorghum_01.pdf

32 | P a g e 
GUIYING. L.. WEIBIN. G.. HICKS. A.. CHAPMAN. K. R.. 2003. A training manual for sweet sorghum. FAO-TCP/CPR/0066. 1-73. Erişim: 31.10.2013. http://ecoport. org/ep? Search Type= earticle View\&earticleId=172\&page $=-2(31.10 .2013)$

KARAYILMAZLAR. S.. SARAÇOĞLU. N.. ÇABUK. Y.. KURT. R.. 2011. Biyokütlenin Türkiye'de enerji üretiminde değerlendirilmesi. Bartın Orman Fakültesi Dergisi. 13 (19):63-75.

KÖPPEN. S.. REINHARDT. G.. GARTNER. S.. 2009. Assessment of energy and greenhouse gas inventories of Sweet Sorghum for first and second generation bioethanol. Environment and Natural Resources Management series. 30. FAO. Rome. 1-86.

LYND. L.R.. CUSHMAN. R.H.. NICHOLS. R.J.. WYMAN. C.E.. 1991. Fuel ethanol from cellulosic biomass. Science. 251: 1318-1328.

LYND. L. R.. 1996. Overview and evaluation of fuel ethanol from cellulosic biomass: technology. economics. the environment. and policy. Annual Review of Energy and the Environment. 21: 403465 .

REDDY. B.V.S. AND SANJANA. R.P.. 2003. Sweet sorghum: characteristics and potential. International Sorghum and Millets Newsletter. 44:26-28.

REDDY. B.V.S.. RAMESH. S.. REDDY. P.S.. RAMAİAH. B.. SALIMATH. P.M.. KACHAPUR. R.. 2005. Sweet sorghum-a potential alternate raw material for bio-ethanol and bioenergy. International Sorghum and Millets Newsletter. 46: 79-86.

SOLEYMANI. A.. ALMODARES. A.. SHAHRAJABİAN. M.H.. 2013. The effect of increase in plant density on stem yield. sucrose content and ethanol yield in two sweet sorghum cultivars. İnternational Journal of Agronomy and Plant Production. 4 (4):642-646.

TSUCHİHASHİ. N. AND GOTO. Y.. 2004. Cultivation of sweet sorghum (Sorghum bicolor (L.) Moench) and determination of its harvest time to make use as the raw material for fermentation. practiced during rainy season in dry land of Indonesia. Plant Production Science. 7(4): 442-448.

YAŞAR. B.. 2009. Alternatif enerji kaynağı olarak biyodizel üretim ve kullanım olanaklarının Türkiye tarımı ve AB uyum süreci açısından değerlendirilmesi. Çukurova Üniversitesi. Fen Bilimleri Enstitüsü. Tarım Ekonomisi Anabilim Dalı. Doktora tezi.1- 210s. 